\title{
Investigating the effect of empowerment aspects on the competence level and suc- cess of primary school principals
}

\author{
Hamidreza Rezazadeh Bahadoran ${ }^{a^{*}}$ and Mahsa Nazari ${ }^{\mathrm{b}}$
}

${ }^{a}$ Assistant Professor, Department of training science, Central Branch, Islamic Azad University, Tehran, Iran ${ }^{b}$ Masters Student, Department of training science, Central Branch, Islamic Azad University, Tehran, Iran

\section{CH R O N I C L E}

Article history:

Received: November 26, 2017

Received in revised format:

March 31, 2018

Accepted: April 4, 2018

Available online:

April 4, 2018

Keywords:

Competence

Empowerment

Principal

Elementary school

\author{
A B S T R A C T
}

\begin{abstract}
The purpose of this study is to investigate the effect of empowerment aspects on the competence level and success of the primary school principals in Pakdasht city in Iran. This research is a descriptive-survey method and in terms purpose is practical. The statistical population of this study consisted of principals of the primary schools in Pakdasht city. The total number of primary school principals in this city is 135 people ( 75 male schools and 60 female schools). As data gathering tool, a researcher-made questionnaire was used. In order to analyze the validity of the questionnaire in this study, the Content Validation Method was used in which the questionnaires were first examined by the experts and the necessary corrections were made. The reliability of the questionnaire was evaluated using Cronbach's alpha coefficient. Research hypotheses were tested using structural equation modeling and AMOS software. The results show that competence and effectiveness aspects affect competence and success of principals of the Pakdasht elementary schools. Autonomy affects the competence level of elementary school principals in Pakdasht city but does not affect principals' success. Meaningfulness aspect did not affect principals' competency however it is effective on principals' success in Pakdasht elementary schools. Trust aspect was not effective on the Pakdasht elementary schools principals' competence and success.
\end{abstract}

(C) 2018 by the authors; licensee Growing Science, Canada

\section{Introduction}

Nowadays, as all organizations are somehow affected by rapid technological advancement, they have to make changes in line with this progress in all aspects of their organizations in order to maintain their existence (Appelbaum et al., 2015). The fact is that today's work environments are under successive and extend changes (Meng et al., 2015). Organizations are redesigned to act more quickly, be more effective, and more flexible, teams are constantly on progress, employees are at the center of attention, and these are the main components of organizations (Arogundade \& Arogundade, 2015). Organizational experts have come to the conclusion that the success and failure of an organization largely depends on the quality of its principals. Several factors affect the principals' success, some of these factors are related to the principal's attributes and personal characteristics (Azzemou \& Noureddine, 2018).

* Corresponding author

E-mail address: rezazade1390@gmail.com (H. Rezazadeh Bahadoran) 
Various ideas have been expressed by management experts in this context (Robelen, 2009). Other factors affecting the principals' success are organizational factors, including: organizational goals and plans, organizational structure and organization resources. Some other factors that affect the principals' success are environmental and non-organizational such as economic, socio-cultural, and political-legal factors (DiPaola et al., 2004). Principals are responsible for providing and guaranteeing efficient utilization of the resources and facilities of their organizations and the continuous improvement of the status of these organizations is the result of their success (Robelen, 2009). Principals' efficiency and success, depend on the set of capabilities and competencies related to various occupational aspects, or even, according to some of management experts reasoning and it is exclusively considered based on the reliance of individuals associated with the occupational funds.

Empowering principals is one of the most important principals' needs and it is a significant potential capacity for optimal use of employee abilities and developing creativity and innovation in carrying out activities and improving the organization in general (Khany \& Tazik, 2016). Management of organizational transformation has introduced the principals' empowerment as an effective strategy to improve human resources performance (Conger \& Kanungo, 1988; Alnaser et al. 2018). They believe that empowerment of human resources is one of the new age attitudes that organizations apply nowadays and in fact it is the answer to the critical needs of contemporary management.

Empowerment is one of the most promising concepts in the business world that has been considered less, but it has now become the topic of the day. In spite of many discussions about the benefits of empowerment, its exploitation is negligible. Although empowerment allows principals to use the knowledge, skills and experience of everyone within the organization, but a few number of principals and groups know how to create empowerment culture (Blanchard et al., 1999). Empowerment begins by making some changes in beliefs, thoughts and attitudes. This means, principals must be convinced that they have the ability and competence to perform their tasks successfully and feel that they have the freedom to act and independence in carrying out their activities, and believe that they have the ability to influence and control the job results. They should feel that they pursue meaningful and worthwhile career goals (Shor, 2012). A prerequisite technique for achieving these goals is motivated and empowered principals. Thus, organizations in today's complex and dynamic world must find this potential and use it. Empowered principals improve the organizations and the way they work, put feelings in their lives and works, and their engagement with this subject makes a continuous improvement in systems and processes (Ellsworth, 1989).

Therefore, considering the importance of two factors, empowerment and competence, in the performance of principals, in this research, the effect of empowerment and competence of the principals' success in elementary schools in Pakdasht city in Iran is investigated. The city of Pakdasht, one of the marginal areas of city of Tehran, is home to diverse cultures and tribes with an immigrant, industrial, and labor characteristics, known as a multicultural or multi-ethnic region due to its texture and population. It can be stated that the educational system in this city has always faced many challenges, which, in order to achieve its goals and a dynamic educational system, especially at schools, we require efficient and competent principals to deal with future challenges. Considering the positive effects of principals' empowerment, the present study intends to examine the effects of empowerment aspects on the competence level and principals' success in the city of Pakdasht, in order to provide valuable resources for the success of the principals of this city in coping with coming challenges. In fact, the mental issue of the researchers began with attention to the empowerment factors and draw the attention to this point that which factors can affect the competence level and success of principals, so the present study has a comprehensive view to answer this question: "how do different empowerment's characteristics affect the level of competence and success of principals in elementary schools in Pakdasht?". 


\section{Literature review}

Arogundade and Arogundade (2015) studied the relationship between psychological empowerment and job satisfaction among employees. The purpose of this study was to prove the effectiveness of different aspects of psychological empowerment (meaningfulness, competence, self-determination and effectiveness) on employee's job satisfaction. The results of this study showed that the psychological empowerment aspects together were accounted for $43 \%$ of variance in job satisfaction. However, different aspects of job empowerment had different shares of job satisfaction variance. The beta calculation showed that the highest variability was related to competence $(\beta=0.42)$, followed by effectiveness $(\beta=0.33)$ and then meaningfulness $(\beta=0.16)$, and self-determination had the lowest beta $(0.06=$ beta $)$. Appelbaum et al. (2015) conducted a research with the purpose of effective factors that are related to the initial ability of the staff in success and failure. Khani and Tazik (2015) examined the relationship between psychological empowerment, teachers' job satisfaction and trust. The results of this study indicated that psychological empowerment was directly related to job satisfaction. However, trust, through job empowerment was indirectly related to job satisfaction. Lin and Chang (2015) conducted a research with the goal of the relationship between empowerment and employees' job satisfaction in Technology Industry in China. This study showed that empowerment had a meaningful effect on job satisfaction. The effect of empowerment on the job satisfaction in different sizes of companies was significantly different. In small scale companies, meaningfulness and empowerment aspects had a significant effect on job satisfaction. However, in moderate companies, meaningfulness and effectiveness maintained a significant impact on job satisfaction.

Meng et al. (2015) examined the relationship between perceived structural empowerment, psychological empowerment, exhaustion and intention to stay in a nursing job. Based on structural modeling, structural empowerment and psychometric empowerment, had a positive and significant effect on the intention of staying in nursing jobs and had a negative effect on job burnout. Chan et al. (2013) conducted a research with the goal of analyzing the relationship between motivational empowerment and competency with the job performance of project principals in an organization in China. Findings supported the relation between competency and alignment and their effect on principals' job performance. Stanley et al. (2013) explored the relationship between the alignment and control location with staff dedication and performance. The results showed that the perceived empowerment dimensions and dedication were affected by the modifier variable, control location. The empowerment aspects had a significant and positive effect on staff dedication. Singh and Sarkar (2012) examined the relationship between psychological empowerment and the development of innovative behaviors in terms of the role of job-adjustment modalities. In this study, 401 teachers were studied in India. Findings of this study showed that self-determination in occupation and organizational levels was directly associated with innovative behaviors. Sufficiency and effectiveness did not have a direct and indirect effect on initiative behaviors. Mendes and Stander (2011) conducted a research to investigate the relationship between job empowerment, job insecurity and employee involvement using correlation. The results showed that there was a definite relationship between job empowerment, job insecurity and employee involvement. The results of multivariate variance analysis showed that job insecurity had a significant effect on the three aspects of psychological empowerment (i.e., competence, meaningfulness and effectiveness), and job involvement. Job insecurity had a moderating effect on the relation between psychological integration and job involvement.

\section{Research hypotheses}

3.1. Main hypothesis: Empowerment aspects affect the level of competence and success of elementary school principals in Pakdasht city.

Sub-hypothesis:

1) Competency aspects affect the level of competence of elementary school principals of Pakdasht city. 
2) Competency aspects affect the success rate of elementary school principals in Pakdasht city.

3) Self-determination aspects is effective on the level of competence of elementary school principals in Pakdasht city.

4) Autonomy is effective on the success rate of elementary school principals in Pakdasht.

5) Effectiveness aspect affects the competence level of elementary school principals in the city of Pakdasht.

6) Effectiveness aspect affects the success rate of elementary school principals in Pakdasht.

7) The meaningful aspect is effective on the level of competence of elementary school principals of Pakdasht city.

8) The meaningful aspect is effective on the success rate of elementary school principals in Pakdasht city.

9) Trust aspect is effective on the level of competence of elementary school principals in Pakdasht city.

10) Trust aspect is effective on the success rate of elementary school principals in Pakdasht city.

\subsection{Research methodology}

Selecting the research methodology depends on the goals and nature of the research and its facilities (Cohen et al., 2002). This research is a descriptive-survey method and in terms purpose is practical. The statistical population of this study was elementary school principals of Pakdasht city in Iran during the year of 2016. The total number of elementary school principals in this city is 135,75 boy's school and 60 girl's school. To determine the sample size, the Morgan sample size determination table was used (Cohen et al., 2002). Sample size is 102 and it is worth mentioning that in this research, stratified sampling method was used to select the representative sample of the society. Approximately 60 women and 75 men were selected randomly. The data gathering tool was a questionnaire that were designed in 3 different parts. The questionnaires included: empowerment aspects with 15 questions (questions 115), a second questionnaire about the competence of principals with 15 questions (16-30) and a third questionnaire about the principals' success rate with 15 questions (31-45), which measure these variable. Based on the Likert spectrum each question is graded from totally agree (5) to completely disagree (1). After the Likert five-point range was scored and its validity was confirmed by two educational management experts, the reliability of the questionnaire was analyzed by SPSS-19 software and Cronbach's alpha coefficient was 0.87 .

\section{Table 1}

The results of Cronbach alpha

\begin{tabular}{|c|c|c|c|c|}
\hline Row & questionnaire & Questions & Aspects & Cronbach's alpha \\
\hline \multirow{6}{*}{1} & \multirow{6}{*}{ Empowerment } & $1-3$ & Competency & 0.585 \\
\hline & & $4-6$ & Autonomy & 0.832 \\
\hline & & $7-9$ & Effectiveness & 0.557 \\
\hline & & $10-12$ & Meaningfulness & 0.606 \\
\hline & & $13-15$ & Trust & 0.644 \\
\hline & & $1-15$ & Total ( Average Alpha ) & 0.845 \\
\hline \multirow{6}{*}{2} & \multirow{6}{*}{ Competency } & $16-18$ & Communication skills & 0.681 \\
\hline & & $19-21$ & Leadership Skills & 0.876 \\
\hline & & $22-24$ & Professional skills & 0.677 \\
\hline & & $25-27$ & Encouragement, innovation and change & 0.879 \\
\hline & & $28-30$ & Development of team activities & 0.888 \\
\hline & & $16-30$ & Total (average alpha) & 0.909 \\
\hline \multirow{5}{*}{3} & \multirow{5}{*}{$\begin{array}{l}\text { Principals' } \\
\text { success }\end{array}$} & $31-35$ & Ability & 0.905 \\
\hline & & $36-40$ & Motivation & 0.897 \\
\hline & & $45-41$ & Opportunity & 0.896 \\
\hline & & $31-45$ & Total (average alpha) & 0.932 \\
\hline & & $1-45$ & Average & 0.873 \\
\hline
\end{tabular}


The value of this statistic indicates that the questionnaire had a high reliability. Data were analyzed using SPSS software version 19 and version 18 of Amos software. The data were analyzed using descriptive and inferential statistics methods. Descriptive statistics were used to survey the demographic characteristics of the respondents. To examine the respondents' demographic characteristics descriptive statistics were used. For analyzing the data and hypotheses testing, inferential statistics methods were used: Multiple regression modeling of structural equations. Table 1 shows the results of Cronbach alpha in different questions.

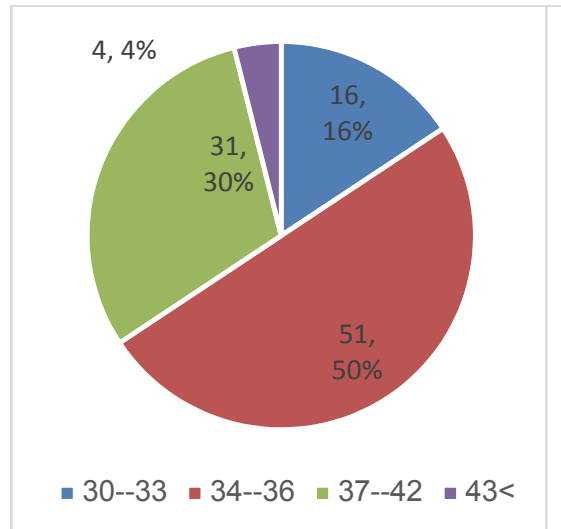

Age

(a)

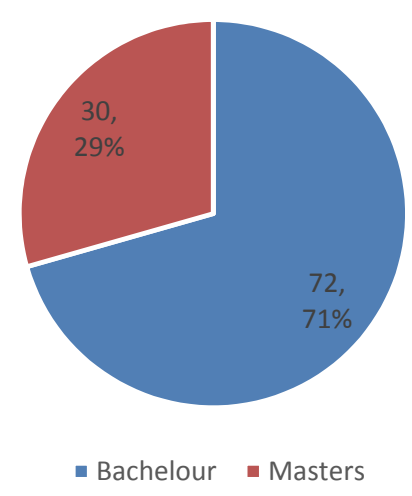

Level of education

(b)

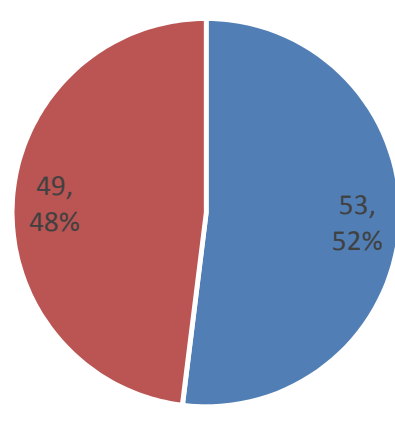

- Male - Female

Fig. 1. Personal characteristics of the participants

Gender

(c)

Fig. 1 presents the demographic characteristics of the sample. As we can see, $52 \%$ of the respondents were male and $50 \%$ of them were female. In addition, about $72 \%$ of the participants hold Bachelor's degree and the rest of them hold a Master's degree of science. In our survey, there were positive and statistically significant relationship between different components of the survey. Regarding the significance of the correlation coefficient between most the empowerment aspects and the success and competency of the principals, to determine the effect level of these aspects on the success and competency of the principals, the regression analysis based on the step-by-step approach was used for the main hypothesis of the present study. In order to determine the strongest predictions of competency and success of school principals, among the empowerment aspects, regression was used step by step. First, the Perth data were removed using the relevant identifying charts (Branch and leaf and box diagrams). Then after confirming the assumption of the normality, the linearity assumption was investigated with two indicators, tolerance coefficient and variance inflation factor (VIF), which represents the lack of linearity between the predictor variables and the reliability of the regression model output. The regression model output shows that there is a meaningful relation among the three aspects of effectiveness, meaningfulness and competence in empowerment and principals' success $\left(R^{2}=0.77\right)$, and these three aspects in total account 0.73 of the principals' success variance. If we want to attribute the value to the real society, meaningfulness in step 3 of 0.73 can explain the success of principals (Adjusted R-Square $=0.73$ ). By examining the standardized regression coefficients, it can be understood that the effectiveness aspect explains a significant part of the criterion variable as compared to the other two aspects (B $=1.21,1.24, \mathrm{~B}=1.39)$. (See Table 2).

\section{Table 2}

The results of step-wise regression analysis in predicting principals' competency

\begin{tabular}{llllllllll}
\hline Predictive variable & step & $\mathrm{B}$ & SEB & Standard coefficient(B) & VIF & $\mathrm{R}^{2}$ equalizer & $\mathrm{R}^{2}$ & $\mathrm{R}$ & $\mathrm{P}$ \\
\hline Effectiveness & first & 1.640 & 0.328 & 0.389 & $0.99(1.00)$ & 0.602 & 0.606 & 0.696 & 0.000 \\
Meaningfulness & second & 1.346 & 0.347 & 0.281 & $0.99(1.00)$ & 0.698 & 0.704 & 0.759 & 0.000 \\
Competency & third & 1.172 & 0.334 & 0.298 & $0.99(1.00)$ & 0.729 & 0.737 & 0.778 & 0.001 \\
\hline
\end{tabular}


The results of the principals' competency regression model show that there was a significant relationship among the three aspects of empowerment, self-efficacy and meaningfulness in empowerment with principals' competency $(\mathrm{R}=0.78)$, and these three aspects in a total account 0.60 of principals' competency variance. If we want to attribute the value to the real society, meaningfulness in step 3 of 0.73 can explain the distribution of principals' merit (Adjusted R-Square $=59$ ). By examining the standardized regression coefficients, it can be noticed that compared to two other aspects $\left(\mathrm{B}^{2}=1.65, \mathrm{~B}^{1}=0.40\right)$ the effectiveness aspect explains a significant part of the criterion variable (See Table 3).

\section{Table 3}

The results of step-wise regression analysis in predicting principals' success

\begin{tabular}{llllllllll}
\hline Predictive variable & step & $\mathrm{B}$ & $\mathrm{SEB}$ & Standard coefficient(B) & VIF & $\mathrm{R}^{2}$ equalizer & $\mathrm{R}^{2}$ & $\mathrm{R}$ & $\mathrm{P}$ \\
\hline Effectiveness & first & 1.653 & 0.353 & 0.396 & $0.99(1.00)$ & 0.479 & 0.485 & 0.696 & 0.000 \\
Autonomy & second & 1.086 & 0.309 & 0.287 & $0.99(1.00)$ & 0.567 & 0.575 & 0.759 & 0.000 \\
Meaningfulness & third & 1.091 & 0.404 & 0.230 & $0.99(1.00)$ & 0.593 & 0.605 & 0.778 & 0.001 \\
\hline
\end{tabular}

In order to test the sub-hypotheses of the research, first, the fitting of the structural equation model of each hypothesis was examined, the results are listed in Table 4. As the table shows, the present study model has a good fit and therefore we test the hypothesis, the results are presented in Table 5.

\section{Table 4}

The results of statistics

\begin{tabular}{llllll}
\hline Indicator & Amount & Standard amount & Indicator & Amount & Standard amount \\
\hline RMSEA & 0.000 & $<0.08$ & GFI & 0.89 & $>0.9$ \\
RMR & 0.038 & $<0.05$ & RFI & 0.92 & $>0.9$ \\
DF/CMIN & 3.84 & $<5$ & IFI & 0.90 & $>0.9$ \\
NFI & 0.89 & $>0.9$ & AGFI & 0.89 & $>0.9$ \\
NNFI & 0.91 & $>0.9$ & PGFI & 0.47 & $<0.5$ \\
CFI & 0.89 & $>0.9$ & & & \\
\hline
\end{tabular}

After evaluating the fitting of the research structural models, we need to examine the hypotheses. According to the information presented in Table 5, 4 hypotheses were rejected and 6 hypotheses were approved or there was no reason to reject them. Table 6 shows the results of the examining the main hypothesis of the survey.

\section{Table 5}

The results of structural equations of the sub-hypotheses of the model

\begin{tabular}{llcrrrrrrr}
\hline \multicolumn{2}{l}{ The path of sub-assumptions } & \multicolumn{2}{c}{ Non-standard coefficients } & $\begin{array}{c}\text { Standard Es- } \\
\text { timated Error }\end{array}$ & $\begin{array}{c}\text { Standard } \\
\text { coefficients }\end{array}$ & t Value & Meaningfulness & Hyp. & result \\
\hline Competency & $\rightarrow$ & Principals' competency & 1.569 & 0.257 & 0.146 & 3.224 & 0.005 & first & accept \\
Competency & $\rightarrow$ & Principals' success & 1.137 & 0.331 & 0.289 & 3.432 & 0.001 & second & accept \\
Autonomy & $\rightarrow$ & Principals' competency & 1.013 & 0.305 & 0.268 & 3.324 & 0.001 & third & accept \\
Autonomy & $\rightarrow$ & Principals' success & 0.186 & 0.253 & 0.049 & 0.734 & 0.463 & fourth & reject \\
Effectiveness & $\rightarrow$ & Principals' competency & 1.278 & 0.427 & 0.306 & 2.996 & 0.003 & fifth & accept \\
Effectiveness & $\rightarrow$ & Principals' success & 1.607 & 0.354 & 0.382 & 4.541 & 0.001 & sixth & accept \\
Meaningfulness & $\rightarrow$ & Principals' competency & 0.756 & 0.46 & 0.159 & 1.643 & 0.1 & sevent & reject \\
Meaningfulness & $\rightarrow$ & Principals' success & 1.299 & 0.382 & 0.272 & 3.405 & 0.001 & eighth & accept \\
Trust & $\rightarrow$ & Principals' competency & 0.205 & 0.338 & 0.055 & 0.608 & 0.543 & ninth & reject \\
Trust & $\rightarrow$ & Principals' success & -0.04 & 0.28 & -0.011 & -0.143 & 0.886 & tenth & reject \\
\hline
\end{tabular}

\section{Table 6}

The results of structural equations of the main hypothesis

\begin{tabular}{|c|c|c|c|c|c|c|c|c|c|}
\hline \multicolumn{2}{|c|}{ The path of sub-assumptions } & \multicolumn{2}{|c|}{ Non-standard coefficients } & $\begin{array}{l}\text { Standard Es- } \\
\text { timated Error }\end{array}$ & $\begin{array}{c}\text { Standard } \\
\text { coefficients }\end{array}$ & t Value & Meaningfulness & Hyp. & \multirow{2}{*}{$\begin{array}{l}\text { result } \\
\text { accept }\end{array}$} \\
\hline Comp & $\rightarrow$ & ls' competen & 1.569 & 0.257 & 0.146 & 3.224 & 0.005 & first & \\
\hline
\end{tabular}

Findings in Table 6 indicate that the effect level of competency aspect on principal's competency was 0.146 which is meaningful. As a result, competency aspect is effective on the principals' competency. 


\section{Discussion and conclusion}

In this research, we have tried to investigate the effect of an increase of empowerment on the competence and success rate of principals of elementary schools. The results of the implementation of stepwise regression as well as structural equation modeling have confirmed the hypothesis. We now analyze the values obtained from each hypothesis. Based on the results and the t-statistic, the job competency aspect affects the competence level of the school principals. The results show that competence aspect has been effective on the success rate of elementary school principals. The result is consistent with the results of Bryk and Schneider (2003). This finding suggests that paying attention to this aspect and taking into account the actions and processes that generate knowledge, skills and abilities in job tasks that are critical to the success of principals in performing those tasks are essential to improve principals' success. Conger and Kanungo (19998) stated that psychological empowerment is important for management stimulating and motivating to compete and innovate in organizations, thus principals' success depends on this to a large extend. Principals tend to be empowered and their ability is related to psychological functions of the school. Empower principals are likely to be more successful, and with a high commitment and effort to create mutual trust among members, they are more likely to create a collaborative atmosphere, teamwork, change and innovation. The more principals' empowerment increase, the sense of competence, which is characterized by the ability of knowledge and skill, will have more potential for principals to be successful.

The results show that the autonomy aspect affects the competence of school principals, which is consistent with the results of the research of Mollahoseini and Arsalan (2009). In explaining the result, one can say that paying attention to the topic of self determination and considering the independence and freedom of the principals in fulfilling their duties to promote their competence and the use of comments and criticisms of school principals is necessary. When a principal has the freedom and authority to perform his duties, he/she can manage the situations, set goals for him/herself, consider criterion for his/her performance, and so on. This process improves the principals' competency aspect day by day because the freedom of action is a motivation and makes the principal to use his/her creativity and to achieve organizational goals, go beyond his/her role and increase the commitment to the day.

The result showed that the autonomy aspect is not effective on the success rate of elementary schools. In explaining the result, we can look into the issue from different perspectives. One aspect is that what autonomy means in terms of statistical sample. If it means single on and defy from the circulars, the above result is logical, because single-one causes failure, not success. Another aspect is that autonomy derives solely from the power of authority to act in the way of doing things, which is not acceptable, since management and competence in having a proper management by delegating rational authority for the incarnation Commitment and competence means not acting in tune.

The results of this study showed that the effectiveness level of Pakdasht elementary school principals maintained a direct impact on the competence level of these schools principals. Indirect evidence in previous studies confirm these results. In this regard, Khany and Tazik (2016) and Meng et al. (2015) investigated the relationship between psychological empowerment and successful job performance and showed that there was a positive and meaningful correlation between successful job performance and psychological empowerment.

The results of this study showed that the effectiveness level of Pakdasht elementary school principals with $95 \%$ confidence had a direct effect on the success level of these schools principals. This finding suggests that by considering this aspect and the extent to which individuals influence the outcomes and results of the organization is necessary to increase principals' success. In explaining the obtained result, it can be said that the sense of being valued and effective in the organizational environment is the driving force of every move and activity that comes from within and does not require control from the 
outside and the tools of this kind. In this case, the unfair behaviors will emerge, then employee and organization become like two souls in one body, and this leads to achieving the organizational goals.

Also, the results of this study showed that meaningfulness aspect did not affect principals' competency. While the perceived meaningfulness of the job in the Pakdasht elementary school principals with 95 percent confidence had a direct effect on the success level of these schools principals. As a result, meaningfulness aspect is effective on principals' success. These results are consistent with the findings of Mendes and Stander (2011). Empowered people feel meaningful. They value the goals of the activity they are engaged in. Their goals and standards are consistent with what they are doing. Activities are considered to be important in their valued system; empowered people are careful about what they are creating, and they believe in it.

This finding suggests that paying attention to the meaningfulness component and considering the mental standards of principals is necessary to increase their success. Since the scope and tasks of principals are very extensive, and the following officials in the field of education can use different ways of empowering the principals to provide many solutions for principals to be successful. On the other hand, one of the education policies for principals to succeed is the development of their empowerment components. Many have come to the conclusion that the use of traditional approaches is not much welcomed by the new class of school principals and it should be changed creatively. Therefore, it can be said that the support of principals by educational brokers has a significant effect on increasing the meaningfulness feeling of the employees, and thus increases their success.

In addition, trust aspect does not affect the competency and satisfaction of elementary school principals. These findings are not consistent with the findings of Arogundade and Arogundade (2015) and Panaccio and Vandenberghe (2009). One of the reasons that may arise in disagreement with the previous results may be due to the non-generalizability of the obtained result in the time and place situations of the research. A wide range of research should be done to generalize and achieve a permanent result.

\section{Suggestions}

1. It is suggested to emphasize more on principals' competency aspects and principals should be tested on a competency-oriented basis so that their capabilities can be improved in order to achieve the organizational goals.

2. It is recommended that continuous education on merit and decent work be done in the education system in order to provide a platform for the development of competency skills in principals, and this approach will be internalized in the educational environment to see their success in affairs we will be served.

3. It is suggested that through the conferral of logical discretion with regard to specialization in principals, the educational organizations delegate part of the way of doing things to principals in order to enhance their creativity and commitment in them every day and need to control and no direct evaluation.

4. It is suggested that educational authorities and policy makers develop educational and charismatic leaders for educational affairs, so that principals are passive and comply with the coarse and the comprehensive guidelines.

5. It is suggested that the sense of meaningfulness and self-worthiness be strengthened in principals so that, while paying attention to their capabilities, principals also consider themselves to be successful in achieving effective goals, and they are not merely an executive force without commitment. It makes the success of the organization more reliable.

6. It is suggested to build trust and confidence in principals and principals feel that all their activities are essential for the advancement of the goals and their abilities to accomplish the work 
are appreciated and their empowerments are emphasized in this regard.It is suggested that educational officials and educators develop broad plans to empower principals, including to build confidence in the implementation process, so that school administrators, while internalizing the outlook of the organization and missions, are able to perform Enhance your affairs.

\section{Acknowledgement}

The authors would like to thank the anonymous referees for constructive comments on earlier version of this paper.

\section{References}

Alnaser, F., Ghani, M \& Rahi, S. (2018). Service quality in Islamic banks: The role of PAKSERV model, customer satisfaction and customer loyalty. Accounting, 4(2), 63-72.

Appelbaum, S. H., Karasek, R., Lapointe, F., \& Quelch, K. (2015). Employee empowerment: factors affecting the consequent success or failure (Part II). Industrial and Commercial Training, 47(1), 23 30 .

Arogundade, O. T., \& Arogundade, A. B. (2015). Psychological empowerment in the workplace: Implications for employees' career satisfaction. North American Journal of Psychology, 17(1), 27.

Azzemou, R., \& Noureddine, M. (2018). Continuous improvement for the firm's competitiveness: implementation of a new management model. Management Science Letters, 8(1), 19-32.

Blanchard, K. H., Carlos, J. P., \& Randolph, W. A. (1999). The 3 keys to empowerment: Release the power within people for astonishing results. Berrett-Koehler Publishers.

Bryk, A. S., \& Schneider, B. (2003). Trust in schools: A core resource for school reform. Educational leadership, 60(6), 40-45.

Cohen, L., Manion, L., \& Morrison, K. (2002). Research Methods in Education. Routledge.

Conger, J. A., \& Kanungo, R. N. (1988). The empowerment process: Integrating theory and practice. Academy of Management Review, 13(3), 471-482.

DiPaola, M., Tschannen-Moran, M., \& Walther-Thomas, C. (2004). School principals and special education: Creating the context for academic success. Focus on Exceptional Children, 37(1), 1.

Ellsworth, E. (1989). Why doesn't this feel empowering? Working through the repressive myths of critical pedagogy. Harvard educational review, 59(3), 297-325.

Khany, R., \& Tazik, K. (2016). On the relationship between psychological empowerment, trust, and Iranian EFL teachers' job satisfaction: The case of secondary school teachers. Journal of Career Assessment, 24(1), 112-129.

Lin, C. T., \& Chang, C. S. (2015). Job satisfaction of nurses and its moderating effects on the relationship between organizational commitment and organizational citizenship behaviors. Research and Theory for Nursing Practice, 29(3), 226-244.

Mendes, F., \& Stander, M. W. (2011). Positive organisation: The role of leader behaviour in work engagement and retention. South African Journal of Industrial Psychology, 37(1), 1-13.

Meng, L., Liu, Y., Liu, H., Hu, Y., Yang, J., \& Liu, J. (2015). Relationships among structural empowerment, psychological empowerment, intent to stay and burnout in nursing field in mainland China-based on a cross-sectional questionnaire research. International journal of nursing practice, 21(3), 303-312.

Mollahoseini, A., \& Arsalan, E. (2009). Examine the relationship between organizational effectiveness of departments and employee empowerment in government agencies Rafsanjan city. Development and Capital, 2(4), 117-140. [In Persian]

Panaccio, A., \& Vandenberghe, C. (2009). Perceived organizational support, organizational commitment and psychological well-being: A longitudinal study. Journal of Vocational Behavior, 75(2), 224-236.

Robelen, E. W. (2009). Studies explore secrets of principals' success. Education Week, 29(14), 1. 
Shor, I. (2012). Empowering education: Critical teaching for social change. University of Chicago Press.

Singh, M., \& Sarkar, A. (2012). The relationship between psychological empowerment and innovative behavior. Journal of Personnel Psychology, 11(3), 127-137.

Stanley, L., Vandenberghe, C., Vandenberg, R., \& Bentein, K. (2013). Commitment profiles and employee turnover. Journal of Vocational Behavior, 82(3), 176-187.

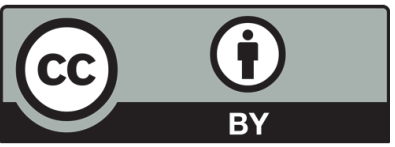

(C) 2018 by the authors; licensee Growing Science, Canada. This is an open access article distributed under the terms and conditions of the Creative Commons Attribution (CC-BY) license (http://creativecommons.org/licenses/by/4.0/). 